\title{
Reflexões sobre parto ativo, corpo e família a partir da obra o Anti-Édipo de Deleuze e Guatarri
}

\author{
ANA CAROLINA NOFFKE ${ }^{1}$
}

O presente trabalho busca fazer um exercício de reflexão em torno das ideias apresentadas pelos autores de $O$ anti-Édipo (DELEUZE; GUATTARI, 2011), adequando estas aos problemas que permeiam as particularidades de cada um, ou seja, experimentando. Somos convidados pelos autores a não interpretar, mas sim, experimentar o livro. De que forma o livro pode nos servir? O que podemos fazer com ele? Como podemos experimentá-lo? Todo o processo de investigação culmina em um leque de possibilidades de experimentação; uma pluralidade de sentidos. $\mathrm{O}$ livro tem como base a dimensão do socius, que é uma espécie de movimento, ou mesmo a configuração do movimento das formações sociais que atuam sobre ele e que, na obra em questão, nos apresenta três formações: o socius primitivo (corpo da Terra), bárbaros (formação despótica) e civilizados (capitalismo). Cada socius possui sua peculiaridade e sua forma de se relacionar com o desejo ${ }^{2}$. No socius primitivo o que condiciona o desejo é a terra; é ela que apresenta seus códigos e dessa forma condiciona o selvagem. Já nos bárbaros o desejo é regulado pela vontade do soberano, apresentando aí o surgimento do Estado e de instituições familiares. Nos civilizados o que opera sobre o desejo é o capital; o desejo se realiza na produção de capital e em contrapartida, este pode se transformar na causa indireta do desejo. Para contextualizar o desejo, Deleuze e Guattarri nos apresentam o conceito de agenciamento ${ }^{3}$ e a tematização de três linhas: molar, molecular e de fuga. A linha molar diz respeito a tudo aquilo que é majoritário, dominante; que está ordenado e estabilizado. Um exemplo seria o homem branco, adulto, heterossexual, cristão, cidadão de bem. Já a linha molecular acentua a questão das minorias, dos diferenciais que transitam pelas bordas e que mostram certa aversão à identidades predominantes. A linha de fuga vem para quebrar com todos os padrões, com todas as linhas precedentes. Acoplado a esse contexto, temos as máquinas desejantes ${ }^{4}$ que foram organizadas em famílias quando da chegada das organizações bárbaras. Esse movimento representou uma mudança das questões sociais, do âmbito coletivo para

\footnotetext{
${ }^{1}$ Graduada em Filosofia pela Universidade Estadual do Oeste do Paraná - 2011. Mestre em Filosofia pela Universidade Estadual do Oeste do Paraná - Linha de Ética e Filosofia Política - 2019. E-mail: noffke.a.c@gmail.com.

${ }^{2} \mathrm{O}$ desejo aqui não deve ser entendido dentro dos parâmetros freudianos, mas sim, como produção. Uma força motriz que funciona num movimento de conexão e interrupção de fluxos.

3 A ideia de agenciamento é apresentada no segundo tomo de Capitalismo e Esquizofrênia e diz respeito a tudo aquilo que compõe o desejo; tudo aquilo que dá sentido ao desejo.

${ }^{4}$ Deleuze e Guatarri utilizam o conceito de máquinas desejantes para se referir ao ser humano colocado como máquina acoplada a outras máquinas, máquinas produzindo conexões, máquinas passando fluxos. Tudo em nós cria, faz, corta, torce, processa, produz. Nosso corpo é uma usina. (DELEUZE; GUATTARI, 2011)
} 
o particular. Tudo o que antes era resolvido socialmente foi direcionado ao círculo familiar.

Nosso intuito aqui, no entanto, será focar nas questões relacionadas à família e ao corpo feminino com todas as suas potencialidades, mas principalmente nas questões que relacionam este corpo e esta instituição ao Movimento do Parto Ativo, expondo estes pontos como um possível devir ou forma revolucionária que tenha condições de manter uma atividade molecular no contexto capitalista sem gerar nenhuma família perversa.

A tarefa de abordar questões que vinculam a família e o corpo feminino como forma revolucionária de enfrentamento ao capitalismo torna-se difícil em dias que cada vez mais nos percebemos engolidos pelo capital em cada mínimo detalhe e que o apelo familiar edipiano está, cada vez mais, dominando o âmbito social e político.

Tudo que foi desdobrado sobre o processo familiar na obra de Deleuze e Guattari fizeram emergir uma nova visão sobre o caráter dessa instituição e de como ela foi se moldando ao longo dos tempos até os dias de hoje, inserida em um contexto capitalista, alentada, há muito, pela Psicanálise e pelo mito de Édipo5

Fundamentalmente a constituição da instituição familiar da qual falamos vem ao encontro das mudanças ocorridas no socius, onde no decorrer dos três movimentos apresentados aqui e mais precisamente no capitalismo, encontra, através da Psicanálise, sua sustentação por meio do discurso baseado no mito de Édipo. A condição a qual a Psicanálise lança o contexto familiar é a da alienação, pois acaba, através do dito complexo, encerrando o olhar do paciente no interior da família e separando dessa forma, o desejo dos agenciamentos sociais. A criança é encerrada nas figuras de pai e mãe e seus correspondentes como o seio ou o falo; enquanto o paciente adulto é conduzido a relembrar uma relação com sua infância, com sua criança, a fim de possibilitar uma interpretação por parte do psicanalista. Essa memória no entanto, é encerrada também nas figuras de pai e mãe. Ao que parece, o ser humano está fadado a ser interpretado com base em suas relações familiares e manter no interior dessa relação a falta que ele deve suprir. Ficam de lado portanto, as relações sociais, as formações de Estado, as políticas que envolvem o corpo e a mente e impedem que a experimentação adquira outros territórios. Isso contribui muito para a manutenção da lógica do capital. A família também passa a

\footnotetext{
${ }^{5}$ No século XIX, Sigmund Freud fez uma reinterpretarão do mito de Édipo, circunscrevendo-o na forma do Complexo de Édipo. Segundo Freud, o Complexo de Édipo é um conjunto de desejos amorosos e hostis, que uma criança experimenta em relação aos seus pais. Em sua forma positiva, o complexo é semelhante à história do mito, ou seja, desejo da morte do rival que é a pessoa do mesmo sexo e desejo sexual pela personagem do sexo oposto. Em sua forma negativa, apresenta-se de forma inversa, ou seja, raiva do sexo oposto e amor pelo mesmo sexo. De acordo com o pensamento freudiano, o Complexo de Édipo é vivido entre os três e os cinco anos e desempenha um papel fundamental na estruturação da personalidade e na orientação do desejo humano. Ele ainda ressalta a influência do comportamento dos pais na vida da criança.
} 
ter um caráter de cerceadora ou codificadora dos desejos, contribuindo assim para a manutenção de uma aparência social padronizada.

A proposta aqui apresentada, no entanto, é tentar visualizar a família para além dos moldes de mãe-pai-filho, mas como aquela que serve de base para a educação e sobrevivência do ser humano, seja ela formada por qualquer pessoa, que tenha ou não vínculo de sangue com a criança. O contexto de família que evocamos aqui seria aquele que ampara o surgimento de um novo ser. Como o problema aqui apresentado se dirige a questão do Parto Ativo, a família seria aquela que pode dar suporte a essa nova máquina desejante e que diretamente poderá zelar e orientar para a preservação da vida. Essa noção clarear-se-á no decorrer das investigações aqui apresentadas. Nosso foco, alinhado a isso, se dará também sobre o corpo feminino e de como a partir dele fundam-se novas máquinas desejantes. Também escolhemos o feminino por ser este um corpo que até os dias atuais ainda precisa lutar para se fazer respeitar no mundo, pois é, geralmente, tratado como uma coisa. O que nos interessa mais é saber como esse corpo está colocado no mundo; suas possibilidades, suas potências e, finalmente, de que forma é tratado este corpo no que diz respeito a esperar e gerar uma nova vida. Juntamente a isso, buscamos também entender como é vista a criança que nasce e de que forma ela é recebida pelo mundo e pela família. Nesse caminho, encontramos e alinhamos a este trabalho, como forma revolucionária de resistência ao capitalismo - à cristalização do Estado como excludente das diferenciações e a axiomatização do nascimento - os Grupos de Apoio ao Parto Ativo.

O conceito de Parto Ativo foi criado por Janet Balaskas, autora do livro Parto Ativo (BALASKAS, J. 1980) entre outras publicações de mesmo teor. A ideia defendida por Balaskas é de que a mulher possa ser livre durante o trabalho de parto. Para que possa se movimentar e fazer o que sente necessidade, sem intervenções desnecessárias que visam apenas acelerar o processo. Em outros termos, o parto ativo se orienta pelo princípio de que a mulher pode ser a dona de seu próprio corpo e de que tem conhecimento e condições suficientes para exercer essa postura, mesmo que 'apenas' intuitivamente. A ideia do parto ativo tem sua força inicial nos anos 70 quando as condições padronizadas hospitalares sob as quais as mulheres deveriam tentar o parto normal eram: separação do companheiro, salas de pré-parto coletivas sem privacidade, impossibilidade de movimentação, soro com hormônios e intervenções para acelerar o parto, período expulsivo com a mulher deitada de costas e pernas amarradas na perneira (o que reduz em 40\% o espaço para a passagem do bebê e diminui a circulação para mãe e feto), comandos para fazer força, equipe pressionando a barriga da mulher, corte rotineiro no períneo, entre outros. As mulheres ficavam assim divididas entre aceitar tais condições ou optar por uma cesárea. 
De qualquer forma a questão aqui é refletir sobre o papel da mulher nesse contexto. Ficar alienada de seu corpo, essa é a condição para o parto naquelas condições. Já está tudo decidido pelo médico, e em vista do conforto deste e não da mãe e do bebê. Janet vai contra essa situação com o conceito de parto ativo. Ao analisarmos mais profundamente, podemos perceber que o agenciamento feito pela mulher/mãe é principalmente o de posicionar seu corpo diante do mundo que o reprime, o coloca como incapaz, defeituoso, promíscuo. É enxergar neste, toda a potência e confiança que nunca lhe foi dada, não se restringindo apenas ao parto, ao processo de nascer, mas criando toda uma atmosfera que proporciona uma percepção mais aprofundada sobre o próprio corpo. Quando a mulher agencia todo esse processo em torno do parto, sua intenção primeira é a de respeito. Respeito para com o seu corpo, para com o corpo do bebê e principalmente para oferecer respeito e acolhimento a esse novo ser que nasce. Uma mulher que busca se conscientizar sobre seu próprio corpo para o trabalho de parto, pode adquirir com isso, uma capacidade de se posicionar no mundo para além do papel estigmatizado que ocupa. Não queremos aqui defender que todas as mulheres devem optar por um parto ativo e nem que todas deveriam passar pelo processo de maternidade. Focamos apenas no aspecto revolucionário que podemos retirar das situações aqui colocadas e de como o corpo feminino pode deslocar a mulher para outra dimensão na sociedade. Tanto para uma mulher que é ou será mãe, como para uma que não tem vontade alguma de o ser, conhecer o próprio corpo é fundamental. Percebemos que nos dias atuais as mulheres estão continuam manifestando cada vez mais insatisfações com abusos e repressões sobre o próprio corpo ${ }^{6}$. No entanto, colocamos a situação do parto ativo (normal) como uma possibilidade de oferecer tanto a mulher quanto ao bebê, a família e a equipe que a acompanha, uma experiência, um acontecimento. Afirmamos o parto como um ritual de passagem, como aqueles citados nos estudos de $O$ anti-Édipo (DELEUZE; GUATTARI, 2011, cap. III), formado pela tríade: olho, voz, grafia. Essa tríade é a figuração do teatro da crueldade, citado pelos autores na mesma obra, extraída do pensamento de Antonin Artaud e que, por sua vez, diz respeito a uma simbologia que atingia a todos os expectadores de um ritual: sendo a grafia e a voz independentes entre si, sem supremacia de uma sobre a outra, e onde o olho que a tudo observava tirava do ritual ali exposto toda sua significação. "Importa que, através de meios seguros, a sensibilidade seja colocada num estado de percepção mais aprofundada e mais apurada. É esse o objetivo da magia e dos ritos" (ARTAUD, A. 2006, p. 104).

\footnotetext{
${ }^{6}$ Relato de mulheres que foram abusadas pela equipe médica e outros atores, durante o trabalho de parto: http://epoca.globo.com/vida/noticia/2015/o8/vitimas-da-violencia-obstetrica-o-lado-invisiveldo-parto.html; Apresentação de trechos do filme $O$ Renascimento do Parto de Érica de Paula e Eduardo Chauvet, seguido de debates: https://www.youtube.com/watch?v=YEpqywwGpBA - Filme completo em: www.netflix.com (Última visualização em 03/03/2021).
} 
Com essa passagem, Artaud não se referia ao processo de parto, mãe-bebê, mas nos arriscamos a sincronizar nossas ideias sobre o parto com a passagem acima citada oferecendo assim uma ótica, de como o parto em questão pode ser visto como um ritual que, baseado na atividade de dois corpos, oferece à percepção uma pluralidade que sugere algo novo. Algo que nos venha de fora e que mude as lentes com as quais vemos o mundo.

Como nos propomos a não sustentar romantismos em torno da família, maternidade e nascimento, colocamos o nascimento agora dentro do quadro mercantil em que é considerado um processo natural, corriqueiro e que já teve suas atividades, axiomatizadas pelo capital. A axiomática do capital desdobra-se a partir da lógica de funcionamento do capitalismo, que consiste na estimulação à produtividade, competitividade e relações de acúmulo. "A axiomática do capital atua no material e no imaterial, modulando as condutas na mesma marcha incessante da lógica da produtividade, por mais que elas possam adquirir as mais distintas roupagens" (HUN, 2015, p. 166). Tal processo pode ser facilmente apreendido no contexto aqui sugerido, tendo como exemplo a cesárea. Não defendemos a anulação da cesárea, não buscamos voltar à selvageria, abolir os processos de desenvolvimento tecnológico e tampouco defendemos que as mulheres devem sofrer até a exaustão já que optaram por serem mães. O que reclamamos aqui é que os avanços tecnológicos sejam utilizados para a supressão de algumas necessidades de mãe e filho e não para controlar e adequar a vida aos agenciamentos do capital. Vivemos hoje, mais do que nunca, em uma sociedade patriarcal que se utiliza da tecnocracia para estipular, além de tudo o mais, quem nasce, como nasce e quando nasce. A mulher é meramente um ser que carrega em seu ventre outro ser, como sempre foi. Quase um material que será levado à linha de produção a fim de que o médico transforme toda essa insignificância em um "milagre da vida". É isso que representa a cesárea nos dias atuais. Um médico consegue fazer de 6 a 8 cesáreas por dia. Enquanto que o parto normal não possibilita estipular seu tempo de duração e nem quando este vai começar. Isso exige do médico uma disposição muito maior. A maioria deles não está disposta e então expõe para a mulher apenas as vantagens de uma cesárea e os riscos e impedimentos para fazer um parto normal. O médico tira da mulher e da criança que vai nascer todo o poder de percepção e atuação do próprio corpo. Não há confiança nestes corpos. O médico é o senhor da vida e a ele cabe decidir sobre as capacidades dos corpos alheios. Todo esse processo reduz o ritual do nascimento a uma cifra, pois se pode contabilizar o tempo de duração do parto, adequando isso a produtividade imposta pelo capital, ou seja, quanto mais cesáreas o médico conseguir fazer, mais organizada estará sua agenda e, portanto, mais controle ele terá sobre seus lucros. Não só a cesárea representa essa axiomática, mas também podemos abordar a questão do parto humanizado. Este tem as mesmas premissas do parto ativo, no entanto, está restrito a certa classe econômica, pois depende de uma estrutura especial. O parto humanizado ocorre, 
em grande parte das vezes, na residência da parturiente ou em locais especializados, com alguns familiares, equipe médica reduzida, doulas e pode ser feito na água ou não. Esse processo não é acessível financeiramente à maioria das gestantes e já se tornou por isso, um nicho de mercado.

Desmistificar o papel da obstetrícia invasiva, autoritária e arcaica que reina hoje, por si só já pode ser considerado um ato de resistência. A busca por um vínculo entre mãe e bebê é humanitária, não se restringe apenas ao nascimento, ou a família que irá vivenciar tal vínculo, mas a todo um agenciamento de valores que a criança poderá receber. A primeira infância muitas vezes já está neste pacote desejado. Coletivos como o A Si Fon Fon ${ }^{7}$ representam as creches parentais que se baseiam nas creches parentais francesas criadas nos anos 70. O que se pode observar dentro destes grupos é que o processo de criação da criança também passa por um processo de experimentação dos pais. Não há um manual. Não existem regras, ou se existem como funcionam? Há nesse contexto todo um processo de questionamento e não apenas de costumes reproduzidos. Os pais adeptos a estas mudanças, não podem se furtar dos questionamentos que irão se instalar diante de seus olhos com relação as mais diversas situações da criação. Não estão dispostos a interpretações e sim a experimentações com suas próprias crias. Há hoje em dia uma infância muito mais respeitada e esperada (ao menos por um lado). Sem adentrar em sentimentalismos, mas nos aprofundando na história da infância veremos que esta passou por processos extremos de descaso, opressão e abusos (e que ainda passa). Ainda hoje podemos vê-los, mas há em contrapartida, uma preocupação com estes novos seres que estão chegando. Algumas linhas de fuga estão sendo traçadas. Há também uma abertura no âmbito familiar que tende a se afastar do aspecto familista (família nuclear) perpetuado até hoje. Esse cenário familista diz respeito àquela condição imposta pelo surgimento do Estado, de que os problemas da família seriam resolvidos pela família, sob o comando do pai e que esse modelo familiar seria atravessado por toda a sociedade, sendo reconhecido até mesmo nas relações que o Estado mantém com os seus. Acompanhamos isso no golpe que ocorreu em 2016 no Brasil, onde a família foi a principal bandeira erguida por nossos parlamentares para exigir a saída da presidenta Dilma. Ao mesmo tempo, isso implica, principalmente nos dias atuais, em uma alienação e negação da família como participante das diversas questões sociais e a inserção destas na lógica do capital. Acreditamos que ao abandonar esse aspecto familista de adequação a identidade, as famílias assumem a responsabilidade diante de uma atmosfera construtivista, experimental, molecular, baseada principalmente no afeto e não no discurso. Como um resgate ao contexto primitivo de criação, onde a criação extrapolava o ambiente familiar e era construída por uma gama de atores que juntos, decidiam por onde caminhar e quais seriam os códigos que deveriam ser ensinados.

\footnotetext{
7 https://coletivoasifonfon.wordpress.com/2016/06/15/conceito/ - (Última visualização em 03/03/2021).
} 
As ideias expostas aqui são apenas um fragmento de tudo que poderia ser abordado como linha molecular que procura sustentar-se diante das molaridades do capitalismo. Que não são determinantes para a definição do ser humano, mas que chamam a atenção para um processo que está acontecendo e pelo qual todos os seres humanos deverão passar para chegar a esse mundo. Seu primeiro contato com o mundo exterior deve ser de dor/medo ou de acolhimento? O corpo feminino pode propiciar um movimento ritualístico juntamente com o corpo da criança, advindo disto uma multiplicidade de afetos e intensidades que culminam em um movimento de respeito e liberdade para ambos. Características estas tão recalcadas pelo capitalismo.

\section{Referências}

ARTAUD, A. O teatro e seu duplo. Trad. Teixeira Coelho / Consultoria da tradução Monica Stahel. 3. ed. São Paulo: Martins Fontes, 2006.

BALASKAS, J. Parto ativo: um guia prático para o parto natural. Trad. Adailton Salvatore Meira. 2. ed. São Paulo: Ground, 2000.

DELEUZE, G. GUATARRI, F. O Anti-Édipo: capitalismo e esquizofrenia. Trad. Luiz B. L. Orlandi, 2. ed. São Paulo: Editora 34, 2011.

HUR, D.U. Axiomática do capital e instituições: abstratas, concretas e imateriais. In Polis e Psique. Porto Alegre, RS - v. 5, n. 3, p. 156-178, 2015. Disponível em: http://pepsic.bvsalud.org/pdf/rpps/v5n3/n5a1o.pdf

NATÁLIO, C. Territorialização / desterritorialização: movimentos cinematográficos. In Atas do II Encontro Anual da AIM, editado por Tiago Baptista e Adriana Martins, Lisboa: AIM, 2013, p. 199-211. Disponível em: http://aim.org.pt/atas/pdfs-Atas-IIEncontroAnualAIM/AtasIIEncontroAnualAIM-18.pdf

PAULA, E. e CHAUVET, E. O renascimento do parto. Direção: Chauvet, E. (2013) Disponível em: https://www.youtube.com/watch?v=YEpqywwGpBA; www.netflix.com

RENNER, E. O começo da vida. Roteiro e direção: Renner, E. 2016. Disponível em: http://ocomecodavida.com.br/

VVAA. Coletivo a si fon. Disponível em:

https://coletivoasifonfon.wordpress.com/2016/o6/15/conceito/

Submissão: 03. 03. 2021 / Aceite: 25. 04. 2021 